\title{
Common Mental Disorders
}

\author{
Risal A
}

Department of Psychiatry

Dhulikhel Hospital - Kathmandu University Hospital

Dhulikhel, Nepal

Corresponding author:

Ajay Risal

Department of Psychiatry

Dhulikhel Hospital - Kathmandu University Hospital

Dhulikhel, Nepal

Email: drajayrisal@gmail.com

\section{Citation}

Risal A. Common mental disorders. Kathmandu Univ Med J 2011;35(3):213-7.

\begin{abstract}
Common mental disorders are a group of distress states manifesting with anxiety, depressive and unexplained somatic symptoms typically encountered in community and primary care settings. Risk factors for these disorders are mainly lower socioeconomic status, psychological illnesses, poor reproductive health, gender disadvantage and physical ill-health. WHO has recommended that treatment of all these disorders should be based in primary care to be more effective and accessible to all the community people. The structure of mental health care in primary care is generally understood in terms of the "pathways to care" model and it plays a major role in countries like ours where community-based mental health services do not exist. Both the psychological and pharmacological therapies are found to be equally effective for treating these disorders. Integration of mental health into primary care can be considered as the stepping stone in the way forward to tackle the barriers and problems in effective management of common mental disorders in the community. The acute shortage of mental health professionals and the relatively low levels of awareness about mental disorders make it mandatory that primary health care should remain the single largest sector for mental health care in low and middle income countries like ours.
\end{abstract}

\section{KEY WORDS}

anxiety, depression, mental disorders

\section{INTRODUCTION}

Common mental disorders are a group of distress states manifesting with anxiety, depressive and unexplained somatic symptoms and are the contemporary equivalent of neurotic disorders typically encountered in community and primary care settings. ${ }^{1}$ They are the leading mental health cause of disability in the global burden of disease. ${ }^{2}$ Crosssectional population-based studies consistently show that the poor and marginalized are at greater risk of having these disorders. ${ }^{3}$

These disorders present either alone or in addition to one or more physical disorders. There are no consistent differences in prevalence between developed and developing countries. GBD (Global Burden of Diseases) 2000 analysis showed that unipolar depressive disorders place an enormous burden on society and are ranked as the fourth leading cause of burden among all diseases, accounting for $4.4 \%$ of the total DALYs (Disability adjusted life years) and $11.9 \%$ of total YLDs (Years lived with disabilities). ${ }^{4}$ By the year 2020, if current trends for demographic and epidemiological transition continue, the burden of depression will increase to $5.7 \%$ of the total burden of disease, becoming the second leading cause of DALYs lost. ${ }^{2}$ Worldwide it will be second only to ischemic heart disease for DALYs lost for both sexes. In the developed regions, depression will then be the highest ranking cause of burden of disease..$^{2,4}$

WHO (World Health Organization) in 1960s-70s brought forward the concept of Severe Mental IIIness (SMIs) comprising mainly of Schizophrenia, Manic depressive psychosis (MDP) and Epilepsy. Later around 1990s, Depression, Anxiety and Unexplained somatic illnesses (nowadays called as somatoform disorders) started being regarded as Minor mental disorders. But the studies and researches consistently showed those so called minor mental disorders were more common and had significant impact being the burden of health care delivery systems. Thus, corrections were made and these three groups of disorders were called collectively as common mental disorders. ${ }^{5}$

A multicenter, cross-national collaborative study conducted by WHO concluded that, in major cultures around the world, psychiatric disorder in primary care is common and associated with substantial levels of disability which was most strongly related to major depression, panic disorder, generalized anxiety, and neurasthenia, which remain within the domain of common mental disorders. ${ }^{6}$

Hence, the common mental disorders can be considered to be under the remit of primary care and can be described using standard diagnostic classification systems like ICD-10 and DSM-IV. ICD-10 primary care version meant for the use by primary health center (PHC) practitioners can be most appropriately used in primary care for the diagnosis of common mental disorders. ${ }^{7-10}$ This concept will no doubt 
provide appropriate and patient sensitive care. ${ }^{11}$ The acceptability and applicability of this concept has been tested in different field trials. ${ }^{12}$

\section{RISK FACTORS}

Various factors were seen to be associated with common mental disorders in different studies, like lower socioeconomic status, psychological illnesses, poor reproductive health, gender disadvantage and physical ill-health. ${ }^{13,14}$ Socio-economic deprivation has been directly related to poor reproductive health, substance use disorders (especially tobacco), chronic medical illnesses which ultimately lead to common mental disorders. ${ }^{15}$ Poverty has been linked with mental and behavioral diseases in many researches which in turn lead to economic hardship forming a vicious cycle. ${ }^{13,15}$ Similarly higher psychological symptom scores at baseline, Sub threshold psychiatric morbidity, Tobacco and alcohol use were found interconnected to each other and with the life events and depressive illnesses. ${ }^{13,16}$ Women reporting abnormal vaginal discharge were seen to have more chance of getting these disorders but no association was seen with sexually transmitted disorders or any other hormonal or biological mechanisms. ${ }^{17-19}$ Females were found to have two to three times more risk than in males and presenting predominantly with somatic complaints and having mixed anxiety depression as the commonest diagnosis. ${ }^{18}$ Higher risk was seen among divorced or widowed female or those who were exposed to intimate-partner violence. ${ }^{14,18} \mathrm{~A}$ depressed female can be seen to be influenced by different vulnerability factors like low autonomy, low family support, low social integration and higher degree of domestic and sexual violence leading to increase in the severity of depression.

Chronic physical illnesses can lead to common mental disorders by different mechanisms, i.e., through direct effect on the brain due to infection, cerebrovascular accidents, trauma, degeneration etc or through the effect of illness burden or comorbidity effecting the treatment and outcome as well as the help seeking behavior and compliance to treatment. Similarly, common mental disorders can lead to physical illnesses as they are associated with risk factors to physical health, e.g., smoking, poor diet, reduced activity and may cause biological changes effecting serotonin metabolism, causing endocrinal effects via cortisol and leading to the immunological changes. ${ }^{20}$

\section{PRIMARY CARE IN MENTAL HEALTH}

Above illustrations point to the fact that mental health problems in general and common mental disorders in particular are an important source of burden worldwide. WHO has recommended that treatment of all these disorders should be based in primary care to be more effective and accessible to all the community people. ${ }^{2}$ Mental health care in primary care has been defined as the provision of basic preventive and curative mental health care at the first point of contact of entry into the health care system. ${ }^{5}$ The structure of mental health care in primary care is generally understood in terms of the "pathways to care" model. ${ }^{21}$ Accessing mental health care involves passing through five levels and three filters between the community and specialist care (Figure 1). The model highlights the decreasing proportion of the total population who access higher levels and the important role of the primary care clinician, whose ability to detect disorder in presenting patients (filter 2 ) and propensity to refer (filter 3), represent key barriers to care. Hence a wide range of mental health problems present in primary care. A distinction has to be made between "severe and long term mental health disorders" (type 1) and "common mental health disorders" (types 2-4) as illustrated in the Table 1. Although primary care has an important role to play in the management of more severe disorders, common disorders are generally viewed as the main remit of primary care.

\section{Level 1. The community \\ All adults who experience an episcole of mental disorder over the course of 1 year}

\section{1st fiter (ilness behavior)}

Lovel 2. Primary care patients (total)

All adults who experience an episode of mental disorder and seek help from a primary care physician

\section{2nd filter (ability to detect disarder)}

Level 3. Primary care patients (detected) Al adults who are considered mentally disordered by their primary care physician, whether or not they satisty research criteria

3rd filter (reforral to mental heaith services)

Level 4. Mental health services (total)

All adults treated by mental health services during tho course of 1 year

4th filter (admission to psychiatric hospital)

\section{Level 5. Mental health services (hospitalized)}

Figure 1. The pathway to psychiatric care: five levels and four filters $^{1}$

Primary care in mental health is guided by the following objectives $^{11}$

a) Effectiveness-Services should improve health and wellbeing.

b) Efficiency-Limited resources should be distributed to maximize health gains to society.

c) Access-Service provision should meet the need for services in the community.

d) Equity-Resources should be distributed according to need. 
Table 1. Mental health disorders in primary care ${ }^{11}$

\begin{tabular}{|c|c|c|c|}
\hline Type & Description & Examples of Disorders & Current care \\
\hline 1 & $\begin{array}{l}\text { Severe mental disorders, unlikely to remit spontaneously, } \\
\text { associated with major disability. }\end{array}$ & $\begin{array}{l}\text { Schizophrenia, Organic disorders, Bipolar } \\
\text { disorder. }\end{array}$ & $\begin{array}{l}\text { Involves both primary and second- } \\
\text { ary care. }\end{array}$ \\
\hline 2 & $\begin{array}{l}\text { Well defined disorders, associated with disabilities for which } \\
\text { there are effective pharmacological and psychological treat- } \\
\text { ments. Disorders may remit, but relapse is common. }\end{array}$ & $\begin{array}{l}\text { Anxious depression, Pure depression, } \\
\text { Generalized anxiety, Panic disorder, } \\
\text { Obsessive-compulsive disorder. }\end{array}$ & $\begin{array}{l}\text { Can usually be managed entirely } \\
\text { within primary care. }\end{array}$ \\
\hline 3 & $\begin{array}{l}\text { Disorders in which drugs have a more limited role, but for } \\
\text { which psychological therapies are available. }\end{array}$ & $\begin{array}{l}\text { Phobias, Somatized presentation of dis- } \\
\text { tress, Eating disorder, Chronic fatigue }\end{array}$ & $\begin{array}{l}\text { Rarely treated within primary care, } \\
\text { only a small proportion of cases are } \\
\text { treated by specialist services. }\end{array}$ \\
\hline 4 & Disorders that tend to resolve spontaneously. & Bereavement, Adjustment disorder & $\begin{array}{l}\text { Supportive help, rather than a spe- } \\
\text { cific mental health skill is needed. }\end{array}$ \\
\hline
\end{tabular}

Different models have been advocated in order to improve the quality of primary mental health care.

1) Training primary care staff ${ }^{5,11}$ - This is the key model which involves the provision of knowledge and skills concerning mental health care to primary care clinicians, mainly directed towards improving prescribing or providing skills in psychological therapy. Training can involve widespread dissemination of information and guidelines or more intensive practice based education seminars. "Defeat depression campaign" as practiced in UK, China and Kashmir region of India use this model of management.

2) Consultation-liaison ${ }^{22}$ - This is a variant of the training model which involves mental health specialists entering into an ongoing educational relationship with primary care clinicians, to support them in caring for individual patients.

3) Collaborative care ${ }^{23,24}$ - Collaborative care can involve aspects of both training and consultation-liaison but also includes the addition of case managers who work with patients and liaise with primary care clinicians and specialists in order to improve quality of care. This model may also involve screening, education of patients, changes in practice routines, and developments in information technology.

4) Replacement/referral ${ }^{11}$ - In this model, the primary responsibility for the management of the presenting problem is passed to the specialist for the duration of treatment. This model is most often associated with psychological therapy.

The primary care clinician has the greatest involvement in the training model, and that involvement decreases in the consultation-liaison, collaborative care, and replacement/ referral models. The degree of involvement of the primary care clinician provides a link between quality improvement models, the pathways to care model, and goals such as access and equity. Assuming equivalent effectiveness, models that put greater focus on increasing the abilities of primary care clinicians have the greatest potential impact on access and equity. This is because these models can most readily influence filter 2 and treatment at level 3, which can potentially influence the largest numbers of patients, i.e., all the patients with common mental disorders presenting in primary care. ${ }^{11}$

As reported by WHO, experiences in some African, Asian and Latin American countries showed that adequate training of primary health care workers in the early recognition and management of mental disorders can reduce institutionalization and improve clients' mental health. $^{2}$ The quality and quantity of specialist mental health services needed depend upon the services that are provided at the primary health care level. Hence the provision of services needs to be balanced between community care and hospital care. Patients discharged from psychiatric wards (in either general or specialized hospitals) can be effectively followed up by primary health care doctors. It is clear that primary health care plays a major role in countries like ours where community-based mental health services do not exist. ${ }^{25}$

\section{MANAGEMENT OF COMMON MENTAL DISORDERS IN PRIMARY CARE}

Management guidelines group of New Zealand has outlined some recommendations for the management of common mental disorders, especially depression. ${ }^{26}$ It has been suggested that the assessment, support and treatment of such disorders should be culturally appropriate. Use of psychosocial assessment and screening tools prior to the diagnostic interviewing would be supportive for recognition of the disorders. Psychological and pharmacological therapies are found to be equally effective for treating these disorders. ${ }^{27}$ A 'stepped care' approach has been advocated in mild to moderate depressive illnesses in younger population which principally involves choosing the least intrusive intervention required to achieve clinical change for an individual. ${ }^{28}$ It says that it is often possible to 'do more with less', by starting with a low-intensity therapy, monitoring patient response and moving to more intensive treatments only if the problem persists. This model guides treatment using a combination of evidence-based principles and continuous clinical assessment and management involves combination of both the pharmacological and non-pharmacological measures that mostly includes psycho-education, group support and antidepressants.29 Progression through levels of care is determined on the basis of patient response. Support for self-care is additional 
Figure 2. Barriers to effective intervention in primary mental health care. ${ }^{2}$

\begin{tabular}{|c|c|c|}
\hline \multicolumn{3}{|c|}{ Stigma and discrimination } \\
\hline Policy level & \multicolumn{2}{|c|}{ Health systems level } \\
\hline $\begin{array}{l}\text { Extent of the problem dispro- } \\
\text { portionate to the limited mental } \\
\text { health budget. } \\
\text { Mental health policy inadequate } \\
\text { or absent. } \\
\text { - Mental health legislation inad- }\end{array}$ & $\begin{array}{l}\text { Large tertiary institutions } \\
\text { - } \quad \text { Stigmatization } \\
\text { - } \\
\text { - } \quad \text { Poor hospital conditions } \\
\text { - } \quad \text { High costs } \\
\text { - } \quad \text { Inadequate treatment and care }\end{array}$ & $\begin{array}{l}\text { Primary health care } \\
\text { - Lack of awareness, skills, training and super- } \\
\text { vision for mental health } \\
\text { - Poorly developed infrastructure }\end{array}$ \\
\hline $\begin{array}{l}\text { equate or absent. } \\
\text { Health insurance which discrimi- } \\
\text { nates against persons with mental } \\
\text { and behavioral disorders. }\end{array}$ & $\begin{array}{l}\text { Community mental health services } \\
\text { - } \quad \text { Lack of services } \\
\text { - Insufficient resources }\end{array}$ & $\begin{array}{l}\text { Human resources } \\
\text { - Lack of specialists and general health work- } \\
\text { ers with the knowledge and skills to manage } \\
\text { disorders across all levels of care }\end{array}$ \\
\hline & $\begin{array}{l}\text { Psychotropic drugs } \\
\text { - Inadequate supply and distribution of psycho- } \\
\text { tropic drugs across all levels of care }\end{array}$ & $\begin{array}{l}\text { Coordination of services } \\
\text { - Poor coordination between services includ- } \\
\text { ing non-health sectors }\end{array}$ \\
\hline War and conflicts & Urbanization & Poverty \\
\hline
\end{tabular}

feature in this approach. Affordable antidepressants such as fluoxetine are considered the treatment of choice as they are associated with improved clinical and economic outcomes, especially in the short term. ${ }^{30,31}$ The most effective management policy is an ongoing, interactive, contextually relevant continuing education which focuses not only on knowledge, but also on skills and attitudes of primary care physicians. ${ }^{32}$

\section{CHALLENGES IN PRIMARY CARE MANAGEMENT}

The primary care management of these disorders is not without any challenges and problems. ${ }^{26}$ Patients may be reluctant to seek or comply with treatment, due to the stigma associated with mental disorders. The treatment may fail as a result of inadequate dosage and duration of antidepressant therapy or due to failure on the part of clinicians to educate patients about the nature of diagnosis and to support self-management. There may be limited access to psychiatrists and other mental health practitioners and lack of ongoing monitoring and maintenance treatment despite high rates of relapse and recurrence. For more intensive treatments, such as psychological therapies, there is a constant tension between need and treatment availability. WHO report 2012 identified different levels of barriers to implementation of effective intervention for mental disorders in community (Table 2).

\section{THE WAY FORWARD}

In an introductory message of the publication of "Integrating Mental Health into Primary Care: A Global Perspective" by the World Health Organization (WHO) and the World Organization of Family Doctors (WONCA) in September 2008, WHO Director General Dr. Margaret Chan and WONCA President Professor Chris van Weel stated that, "Primary care starts with people. And, integrating mental health services into primary care is the most viable way of ensuring that people have access to the mental health care they need......". ${ }^{33}$ It was highlighted in the publication that mental health care delivered in primary care minimizes stigma and discrimination, and removes the risk of human rights violations that occur in psychiatric hospitals as well as it generates good health outcomes at reasonable costs. This avoids indirect costs associated with seeking specialist care in distant locations. Hence integration of mental health into primary care was considered as the stepping stone in the way forward to tackle the barriers and problems in effective management of common mental disorders in the community. Similar views were found in different publications on the issues of global mental health, more importantly prioritizing the needs of low and middle income countries like ours. ${ }^{34,35}$ More recommendations can be seen in different world health reports. ${ }^{2,5,25,33}$ They have emphasized that the care should shift away from large psychiatric hospitals to community services that are integrated into general health services. Making psychotropic drugs available, training the required health workers, utilizing mass media and starting public awareness campaigns, supporting non-governmental organizations and consumer groups are the other issues raised.

\section{CONCLUSION}

Common mental disorders are the commonest mental health problems that usually present in primary care. The acute shortage of mental health professionals and the relatively low levels of awareness about mental disorders make it mandatory that primary health care should remain the single largest sector for mental health care in low and middle income countries like ours. 


\section{REFERENCES}

1. Goldberg D, Huxley P. Common mental disorders: a biosocial model. London, England: Tavistock/Routledge, 1992.

2. World Health Organization. The world health report 2001-mental health: new understanding, new hope. Geneva: WHO, 2001.

3. Patel V, Kleinman A. Poverty and common mental disorders in developing countries. Bulletin of the World Health Organization 2003; 81: 609-15.

4. Murray $\mathrm{CJL}$, Lopez $\mathrm{AD}$. Progress and directions in refining the global burden of disease approach: a response to Williams. Health Economics 2000; 9: 69-82.

5. World Health Organization. ATLAS: mental health resources in the world 2001. Geneva: WHO, 2001.

6. Ormel J, VonKorff M, Ustun TB. Common Mental Disorders and Disability Across Cultures: Results From the WHO Collaborative Study on Psychological Problems in General Health Care. JAMA 1994; 272:1741-48.

7. Ustun TB, Sartorius N. Mental illness in general health care: an international study. Chichester, England: John Wiley and Sons Ltd., 1995.

8. World Health Organization. The ICD-10 classification of mental and behavioral disorders-clinical descriptions and diagnostic guidelines. World Health Organization, Geneva, 1992.

9. American Psychiatric Association. Diagnostic and statistical manual of mental disorders: DSM-IV. 4th ed. Washington DC: American Psychiatric Association, 1994.

10. World Health Organization. Diagnostic and management guidelines for mental disorders in primary care: ICD-10 Chapter V Primary Care Version. WHO-Hogrefe and Huber, Göttingen, 1996.

11. Bower P, Gilbody S. Managing common mental health disorders in primary care: conceptual models and evidence base. BMJ 2005; 330:839-42.

12. Goldberg D. Epidemiology of Mental Disorders in Primary Care Settings. Epidemiologic Reviews 1995; 17 (1):182-90.

13. Goldberg D. Vulnerability factors for common mental illnesses. British Journal of Psychiatry 2001; 178 (suppl. 40); 169-71.

14. Patel V, Kirkwood BR, Pednekar S. Risk factors for common mental disorders in women: Population-based longitudinal study. British Journal of Psychiatry 2006; 189: 547-55.

15. Patel V, Kleinman A. Poverty and common mental disorders in developing countries. Bulletin of the World Health Organization 2003; 81 (8): 609-15

16. Breslau N, Schultz LR, Johnson EO. Smoking and the risk of suicidal behavior: a prospective study of a community sample. Archives of General Psychiatry 2005; 62: 328-34

17. Prasad J, Abraham S, Akila B. Symptoms related to the reproductive tract and mental health among women in rural Southern India. National Medical Journal of India 2003; 16: 303-8.

18. Patel V, Kirkwood BR, Pednekar S. Gender disadvantage and reproductive health risk factors for common mental disorder in women: a community survey in India. Archives of General Psychiatry 2006; 63:404-13.
19. Piccinelli M, Wilkinson G. Gender differences in depression. Critical review. British Journal of Psychiatry 2000; 177: 486-92.

20. Evans DL, Charney DS, Lewis L. Mood disorders in the medically ill: scientific review and recommendations. Biological Psychiatry 2005; 58:175-189.

21. Goldberg D, Huxley P. Mental illness in the community: the pathway to psychiatric care. London: Tavistock, 1980.

22. Gask L, Sibbald B, Creed F. Evaluating models of working at the interface between mental health services and primary care. $\mathrm{Br} J$ Psychiatry 1997; 170:6-11.

23. Katon W, Von Korff M, Lin E, Simon G. Rethinking practitioner roles in chronic illness: the specialist, primary care physician and the practice nurse. Gen Hosp Psychiatry 2001; 23:138-44.

24. Wagner E, Austin B, Von Korff M. Organizing care for patients with chronic illness. Milbank Q 1996; 74:511-43.

25. WHO-AIMS Report on Mental Health System in Nepal, WHO and Ministry of Health, Kathmandu, Nepal, 2006.

26. Identification of Common Mental Disorders and Management of Depression in Primary Care: Evidence-based Best Practice Guideline 2008. New Zealand Guidelines group, Ministry of Health.

27. Bech P, Cialdella M, Haugh MC. Meta-analysis of randomized controlled trials of fluoxetine vs placebo and tricyclic antidepressants in the short-term treatment of major depression. $\mathrm{Br} J$ Psychiatry 2000; 176: 421-28.

28. Davison GC. Stepped care: doing more with less? J Consult Clin Psychol 2000; 68(4):580-5.

29. Araya R, Rojas G, Fritsch R. Treating depression in primary care among low-income women in Santiago, Chile: a randomized controlled trial. Lancet 2003; 361:995-1000.

30. Patel V, Chisholm D, Hesketh SR. Efficacy and cost-effectiveness of drug and psychological treatments for common mental disorders in general health care in Goa, India: a randomized, controlled trial. Lancet 2003; 361: 33-39.

31. Cohen A. The effectiveness of mental health services in primary care: the view from the developing world. Geneva: World Health Organization, 2001.

32. Patel V, Cohen A. Mental health services in primary care in 'developing' countries. World Psychiatry October 2003; 2 (3):163-64.

33. Integrating Mental Health into Primary Care: A Global Perspective. WHO/WONCA 2008; 21-46.

34. Prince M, Patel V, Saxena S, Maj M. Global Mental Health 1: No health without mental health. Lancet 2007; 370: 859-77.

35. Patel V, Araya R, Chatterjee S, Chisholm D. Global Mental Health 3: Treatment and prevention of mental disorders in low-income and middle- income countries. Lancet 2007; 370: 991-1005. 